\title{
Dynamic Simulation of Variable-Speed Valve-Controlled-Motor Drive System with a Power-Assisted Device
}

\author{
Ming $\mathrm{Xu}^{*}$ - Jing $\mathrm{Ni}$ - Guojin Chen \\ Hangzhou Dianzi University, School of Mechanical Engineering, China
}

The variable-speed electrohydraulic drive has been applied in hydraulic machines having power matching means. However, further development has been restricted by its slow response and poor low-speed behavior. Owing to these disadvantages, a novel drive principle comprising a variable-speed valve-controlled-motor drive with an accumulator-based power assisted unit (PAU) is proposed. The PAU is an energy assisting and recycling device, which can release or absorb hydraulic energy according to the system's requirements. With the aid of PAU, the proposed drive is expected to improve response and control precision compared with the variable-speed drive. The proposed drive principle system is a multi-input-multi-output (MIMO) complicated nonlinear system with time-varying, which increases the control difficulty. A mathematical model of the proposed drive was first derived then a hybrid control strategy was presented. The dynamic simulations of three traditional drives and the novel one were performed using AMESim-Simulink co-simulation models. The four drives have been tested using three common variable-load disturbances. Comparisons of simulation results show that the proposed drive principle system demonstrates a good dynamic performance, which can not only achieve the expected energy saving target, but also significantly improve the response and control precision over the existing variable-speed drive system.

Keywords: variable-speed, energy saving, variable-load, response, hydraulic motor

\section{O INTRODUCTION}

The variable-speed electrohydraulic drive uses a variable-speed electric-motor to drive a hydraulic fixed displacement pump, by adjusting the electricmotor speed to regulate the hydraulic pump output flow rate so as to meet the load-demand. It is a typical power matching hydraulic system. Compared with the conventional pump-controlled-motor drive principle which uses a constant-speed electric-motor to drive a hydraulic variable displacement pump, the variablespeed drive can achieve a large adjustable speed-ratio. In addition, the hydraulic fixed displacement pump has a simpler structure, a longer service life and lower noise than variable displacement pump. The frequency converter was first used to adjust the electric-motor speed. In recent years, the servo-motor was chosen gradually to drive the hydraulic fixed displacement pump. However, the variable-frequency is still the primary technique for its low price and minimal modification to the original hydraulic system. In the past twenty years, the variable-speed drive has been widely studied to be applied in hydraulic machines, such as injection molding machine, hydraulic elevator, wind turbine, shield machine [1] to [3]. Helduser studied the energy saving performance of variablespeed drive used in injection molding machine [4]. $\mathrm{Xu}$ discussed the variable-speed hydraulic elevator [5]. Lovrec explored the application possibilities of variable-speed drive in molding machine [6]. Chiang studied a $2 \mathrm{MW}$ wind turbine based on high-power variable-speed drive technology [7].
However, the variable-speed drive has two critical disadvantages, slow response and poor control precision, which resulting from the large inertia of the electric-motor [8] and hydraulic pump. In order to overcome these problems, a compound drive principle (or called variable-speed valve-controlled-actuator drive) was built, where a proportional directional valve (or a servo directional valve) was added into the variable-speed (variable-frequency) drive system. In the compound drive system, the frequency converter adjusts the electric-motor speed to satisfy the actuator flow-demand and the proportional directional valve controls the actuator position or speed. The compound drive can improve the control precision and lowspeed performance compared to the variable-speed drive system [9]. It can also improve the actuator deceleration process for the short response time of the proportional directional valve. But it is unable to improve the response when accelerating [10]. Therefore, it is mainly applied in hydraulic elevators etc., which do not require a fast response [11] to [12].

The variable-speed electrohydraulic drive with a power assisted unit (PAU) has been proposed in order to improve responsiveness, especially when accelerating. This drive is distinguished from the compound drive by the inclusion of a PAU. The electric motor-pump cannot always speed up as needed when accelerating, so the PAU releases energy to improve the acceleration response. When the actuator is decelerating but the electric motor-pump cannot slow down as needed, the PAU absorbs energy 
for use in the next working cycle. In other cases, the PAU is turned off.

The hydraulic motor is an important actuator in a hydraulic system. It was used mostly in the pumpcontrolled-motor drive system, which normally responds badly and has poor control precision. This paper focus on the modeling and dynamic performance of a variable-speed valve-controlled-motor drive system with a PAU. Three typical variable-load disturbances were implemented to test the dynamic performances of the four drive principles, which are the valve-controlled-motor drive, the variable-speed pump-controlled-motor drive, the variable-speed valve-controlled-motor drive, and the variablespeed valve-controlled-motor drive with a PAU. The purpose is to demonstrate the dynamic performance of the proposed drive principle system compared to the others.

\section{PRINCIPLE OF PROPOSED DRIVE}

Fig. 1 shows the proposed drive principle system, where $p_{\mathrm{e}}, p_{\mathrm{s}}$ indicate the oil pressure of the PAU and of the hydraulic pump outlet respectively. $V_{\mathrm{e}}, V_{\mathrm{g}}, V_{1}$, $V_{2}$ indicate the oil-chamber volume of the PAU, the hydraulic pump outlet, the high-pressure and the low-pressure chamber of actuator respectively. A $n_{\mathrm{m}}$ indicates the rotary speed of actuator, $f_{\text {in }}$ is the input frequency of frequency converter, $u_{\mathrm{d}}$ is the control voltage of proportional directional valve, $u_{\mathrm{t}}$ is the control voltage of proportional flow valve, and $T_{\mathrm{L}}$ is the load-torque.

There are two power sources, the main power source (the electric motor-pump) and the PAU. The main power source is composed of a hydraulic fixed displacement pump, a frequency converter and an electric-motor, where the hydraulic pump is driven by a three-phase asynchronous electric-motor via a frequency converter. Since the main power source often cannot meet the flow-demand of hydraulic motor acceleration, the PAU was added into the variablespeed valve-controlled-motor drive system. The PAU is virtually a valve-controlled-accumulator unit. A bladder accumulator was chosen as the energy storage element for its fast response, simple structure and low price. The proportional flow valve controls the flow rate assisted or recycled. It can also be a servo valve or a high-speed on/off valve. The relief valve is used as a safety valve. The PAU is a semi-active device, whose discharging \& absorbing function depends on the pressure difference between the PAU and hydraulic pump outlet, so the pressures $p_{\mathrm{e}}$ and $p_{\mathrm{s}}$ should be measured. A hydraulic motor, whose type model is the same as the actuator, is used for a loading pump. Different loads can easily be simulated and produced by setting the cracking pressure of the loading valve (the proportional relief valve in the loading system).

As shown in Fig. 1, the main purpose of the proportional directional valve is to accelerate the response when decelerating. The spool-opening of the proportional directional valve can be decreased rapidly, thus speeding up the hydraulic motor response when decelerating. In general cases, the proportional directional valve maintains its maximum spool-opening. In addition, the rotational direction of hydraulic motor can be conveniently switched by using the proportional directional valve. Therefore, the hydraulic pump is only needed to rotate toward one direction so as to reduce the impact caused by switching directions.

The four compared drive principle are explained as follows.

1. Valve-controlled-motor drive. The PAU is closed (the flow valve in the PAU is closed). The electric-motor speed maintains $1500 \mathrm{r} / \mathrm{min}$ continuosly. The proportional directional valve controls the flow rate inpouring into the hydraulic motor chamber therefore it can control the speed of the hydraulic motor. The relief valve works continuosly.

2. Variable-speed pump-controlled-motor drive. The PAU is closed. The speed of hydraulic fixed displacement pump can be adjusted via the frequency converter. The proportional directional valve only controls the rotational direction of hydraulic motor with maximum spool-opening.

3. Variable-speed valve-controlled-motor drive. The PAU is closed. The proportional directional valve and the speed-controlled hydraulic pump control the hydraulic motor together.

4. Variable-speed valve-controlled-motor drive with a PAU. On the basis of variable-speed valvecontrolled-motor drive, the PAU provides for a better acceleration response. When the actuator is accelerating but the electric motor-pump cannot always speed up as needed, the PAU releases energy to improve the acceleration response. When the actuator is decelerating but the electric motor-pump cannot always slow down as needed, the PAU absorbs energy. In other cases, the PAU is turned off.

The parameters of PAU (i.e. accumulator volume, accumulator precharge pressure, etc.) are very important to the proposed drive system [10]. This paper aims to demonstrate the dynamic performance 


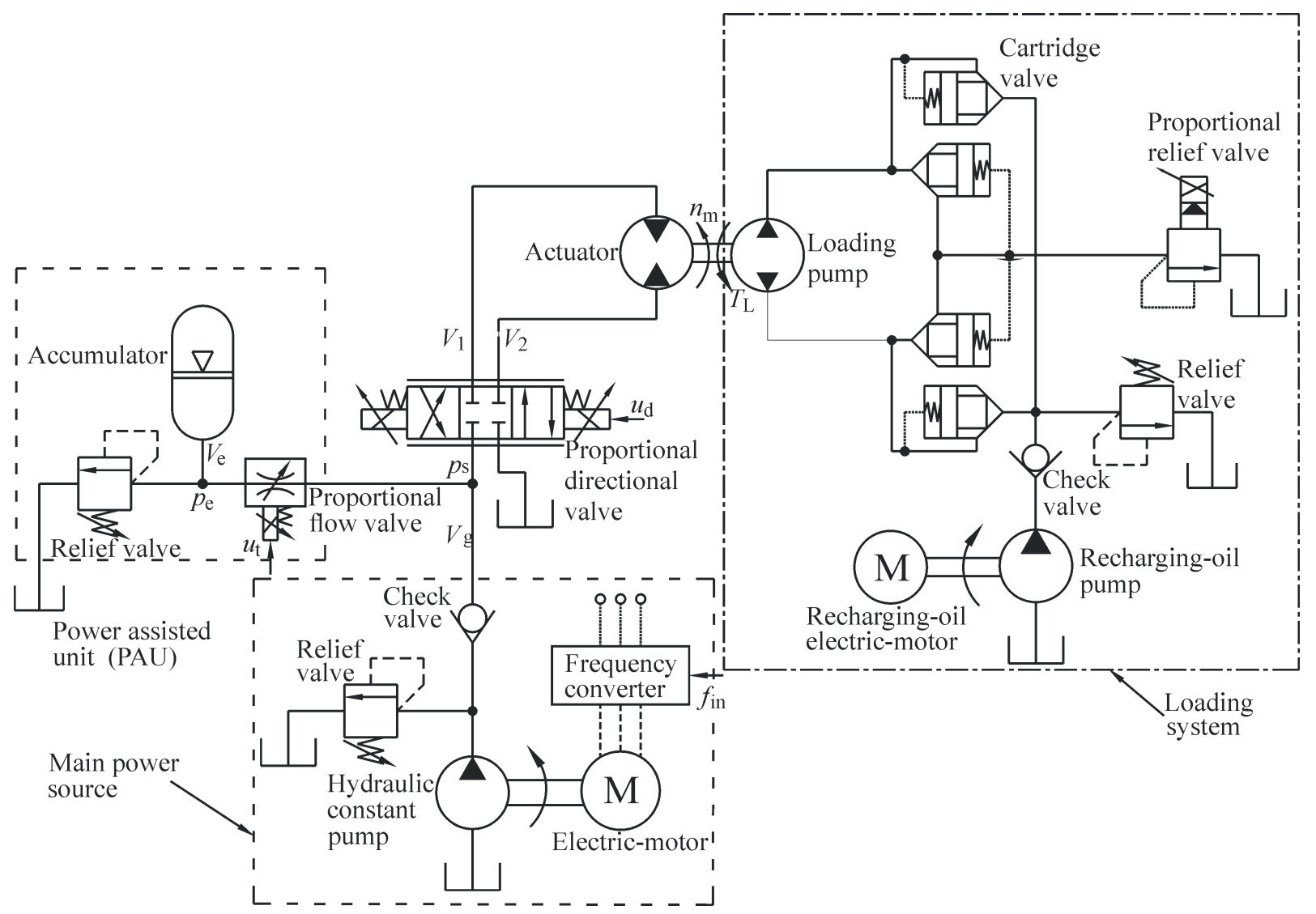

Fig. 1. Principle of variable-speed valve-controlled-motor drive system with a PAU

of the proposed drive system without a general discussion of PAU.

\section{MATHEMATICAL MODEL}

In this section, the mathematical model of proposed drive system is derived.

\subsection{Frequency Converter - Electric Motor}

The frequency converter-electric motor can be represented by Eq. (1).

$$
n_{\mathrm{p}}=\frac{K_{\mathrm{f}}}{T_{\mathrm{IM}} s+1} f_{\text {in }},
$$

where $n_{\mathrm{p}}$ is the rotational speed of hydraulic pump, $K_{\mathrm{f}}$ is the gain coefficient, $T_{\mathrm{IM}}$ is the time coefficient, which increases accompanied by the increment of the electric motor-pump rotational inertia.

\subsection{Hydraulic Fixed Displacement Pump}

The flow rate discharged by hydraulic fixed displacement pump can be represented by the Eq. (2).

$$
Q_{\mathrm{p}}=D_{\mathrm{p}} n_{\mathrm{p}}-k_{\mathrm{tc}} p_{\mathrm{s}},
$$

where $D_{\mathrm{p}}$ is the displacement of hydraulic fixed displacement pump, $k_{\mathrm{tc}}$ is the leakage coefficient.

\subsection{Relief Valve}

The proposed drive system is a power matching hydraulic system, where the relief valve is used as a safety valve. So the mathematical model can be represented by the Eq. (3).

$$
Q_{\mathrm{cr}}=\left\{\begin{array}{cc}
K_{\mathrm{r}}\left(p_{\mathrm{s}}-p_{\mathrm{cr}}\right) \sqrt{p_{\mathrm{s}}} & p_{\mathrm{s}} \geq p_{\mathrm{cr}} \\
0 & p_{\mathrm{s}}<p_{\mathrm{cr}}
\end{array},\right.
$$

where $K_{\mathrm{r}}$ is the gain coefficient of relief valve, $p_{\text {cr }}$ is the preset cracking pressure of relief valve. 


\subsection{PAU}

The principle of PAU is shown in Fig. 2.

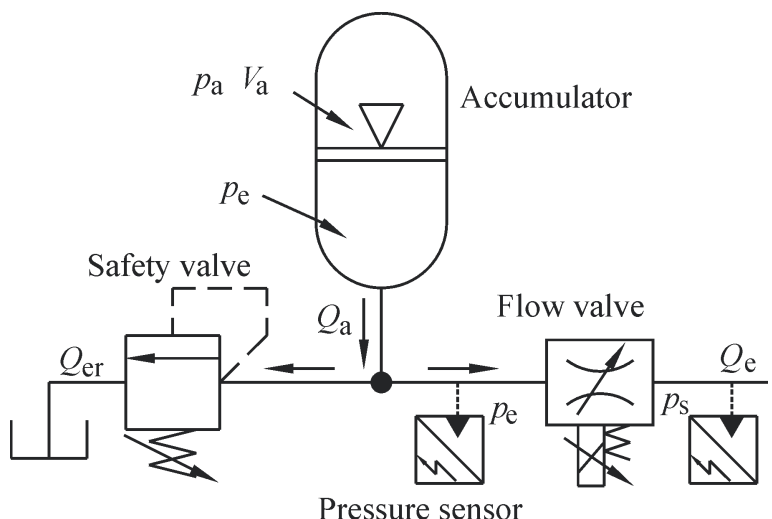

Fig. 2. Principle of accumulator-based PAU

In Fig. 2, $p_{\mathrm{a}}$ is the pressure of nitrogen gas in the accumulator, $V_{\mathrm{a}}$ is the volume of nitrogen gas, $Q_{\mathrm{a}}$ is the oil flow rate discharged or absorbed by the accumulator, $Q_{\mathrm{e}}$ is the oil flow rate discharged or absorbed by the PAU, and $Q_{\mathrm{er}}$ is the overflowing flow rate by the relief valve in PAU. follows.

The modeling of proposed PAU is deduced as

In the proposed drive system, the time required for oil to be discharged or absorbed by PAU is very short, so the nitrogen gas in the accumulator can be supposed to work in an adiabatic process. Eq. (4) can be established by Boyle's law.

$$
p_{\mathrm{a}} \cdot V_{\mathrm{a}}^{1.4}=\text { const. }
$$

The derivation of Eq. (4) is:

$$
1.4 p_{\mathrm{a}} \cdot V_{\mathrm{a}}^{0.4} \frac{\mathrm{d} V_{\mathrm{a}}}{\mathrm{d} t}+V_{\mathrm{a}}^{1.4} \cdot \frac{\mathrm{d} p_{\mathrm{a}}}{\mathrm{d} t}=0 .
$$

Then the oil flow rate discharged by accumulator can be derived such that:

$$
Q_{\mathrm{a}}=\frac{\mathrm{d} V_{\mathrm{a}}}{\mathrm{d} t}=-\frac{V_{\mathrm{a}} \cdot \frac{\mathrm{d} p_{\mathrm{a}}}{\mathrm{d} t}}{1.4 p_{\mathrm{a}}},
$$

and also

$$
p_{\mathrm{a}} \cdot V_{\mathrm{a}}^{1.4}=\text { const } .=p_{\mathrm{a} 0} \cdot V_{\mathrm{a} 0}^{1.4},
$$

where $p_{\mathrm{a} 0}$ is the initial pressure of nitrogen gas in the accumulator, $V_{\mathrm{a} 0}$ is the initial volume of nitrogen gas in the accumulator; both are known.

Using Eq. (6) and (7), Eq. (8) can be deduced.

$$
Q_{\mathrm{a}}=-\frac{p_{\mathrm{a} 0}^{\mathrm{s} /} \cdot V_{\mathrm{aa}} \cdot \frac{\mathrm{d} p_{\mathrm{a}}}{\mathrm{d} t}}{1.4 p_{\mathrm{a}}^{12 / 4}} .
$$

Since the parameter $p_{\mathrm{a}}$ cannot be detected in a physical system, we suppose that $p_{\mathrm{e}}$ is equal to $p_{\mathrm{a}}$ in the discharging or absorbing process of accumulator. Then Eq. (8) can be represented as:

$$
Q_{\mathrm{a}}=-\frac{p_{\mathrm{a} 0}^{5 / 4} \cdot V_{\mathrm{a} 0} \cdot \frac{\mathrm{d} p_{\mathrm{e}}}{\mathrm{d} t}}{1.4 p_{\mathrm{e}}^{12 / 4}} .
$$
by:

The proportional flow valve can be represented

$$
Q_{\mathrm{e}}=C_{\mathrm{d}} \cdot W_{\mathrm{t}} \cdot X_{\mathrm{vt}} \sqrt{\frac{2}{\rho}\left|p_{\mathrm{e}}-p_{\mathrm{s}}\right|} \operatorname{sgn}\left(p_{\mathrm{e}}-p_{\mathrm{s}}\right)
$$

where $C_{\mathrm{d}}$ is the discharge coefficient of flow valve, $W_{\mathrm{t}}$ is the spool area gradient of flow valve, $X_{\mathrm{vt}}$ is the spool displacement of flow valve, $\rho$ is the oil density,

$$
\operatorname{sgn}\left(p_{\mathrm{e}}-p_{\mathrm{s}}\right)=\left\{\begin{array}{cl}
1 & p_{\mathrm{e}}>p_{\mathrm{s}} \\
0 & p_{\mathrm{e}}=p_{\mathrm{s}} . \\
-1 & p_{\mathrm{e}}<p_{\mathrm{s}}
\end{array}\right.
$$

For the flow valve, the relationship between the spool displacement and control voltage can be simplified as:

$$
\frac{X_{\mathrm{vt}}}{u_{\mathrm{t}}}=\frac{K_{\mathrm{tv}}}{\frac{1}{\omega_{\mathrm{t}}} s+1},
$$

where $K_{\mathrm{tv}}$ is the gain coefficient of flow valve and $\omega_{\mathrm{t}}$ is the natural frequency of flow valve.

Putting Eq. (11) into Eq. (10), and defining $K_{\mathrm{t}}=K_{\mathrm{tv}} \cdot C_{\mathrm{d}} \cdot W_{\mathrm{t}} \cdot \sqrt{2 / \rho}$, Eq. (12) can be deduced:

$$
Q_{\mathrm{e}}=\frac{K_{\mathrm{t}}}{\frac{1}{\omega_{\mathrm{t}}} s+1} \cdot u_{\mathrm{t}} \sqrt{\left|p_{\mathrm{e}}-p_{\mathrm{s}}\right|} \operatorname{sgn}\left(p_{\mathrm{e}}-p_{\mathrm{s}}\right) .
$$

The relief valve in PAU can be represented by:

$$
Q_{\mathrm{er}}= \begin{cases}K_{\mathrm{er}}\left(p_{\mathrm{e}}-p_{\mathrm{ec}}\right) \sqrt{p_{\mathrm{e}}} & p_{\mathrm{e}} \geq p_{\mathrm{ec}} \\ 0 & p_{\mathrm{e}}<p_{\mathrm{ec}}\end{cases}
$$

where $K_{\text {er }}$ is the gain coefficient of relief valve, $p_{\text {ec }}$ is the cracking pressure of relief valve.

Ignoring the leakage, the flow in the PAU pipeline is represented by Eq. (14): 


$$
Q_{\mathrm{a}}-\left(Q_{\mathrm{e}}+Q_{\mathrm{er}}\right)=\frac{V_{\mathrm{e}}}{E_{\mathrm{h}}} \cdot \frac{\mathrm{d} p_{\mathrm{e}}}{\mathrm{d} t},
$$

where $V_{\mathrm{e}}$ is the oil-tank volume of PAU (sum of the accumulator oil-tank volume and the PAU pipeline volume), and $E_{\mathrm{h}}$ is the bulk modulus of hydraulic oil.

The relief valve was used as a safety valve in the PAU, which is closed during normal operation, so $Q_{\text {er }}$ can be supposed to zero. The Eq. (14) can be simplified as:

$$
Q_{\mathrm{a}}-Q_{\mathrm{e}}=\frac{V_{\mathrm{e}}}{E_{\mathrm{h}}} \cdot \frac{\mathrm{d} p_{\mathrm{e}}}{\mathrm{d} t}
$$

The mathematical model of the proposed PAU can be described by the Eqs. (9), (12) and (15).

\subsection{Proportional Directional Valve}

The directional valve can be represented as the following linearized equation:

$$
Q_{\mathrm{L}}=K_{\mathrm{qd}} X_{\mathrm{vd}}-K_{\mathrm{cd}} p_{\mathrm{L}}
$$

where $Q_{\mathrm{L}}$ represents the loading flow rate, $p_{\mathrm{L}}$ represents the loading pressure, $X_{\mathrm{vd}}$ represents the spool displacement of proportional directional valve, the flow gain coefficient is $K_{\mathrm{qd}}=\partial Q_{\mathrm{L}} / \partial X_{\mathrm{vd}}$, and the flow-pressure gain coefficient is $K_{\mathrm{cd}}=\partial Q_{\mathrm{L}} / \partial p_{\mathrm{L}}$.

The relationship between the spool displacement and control voltage can be simplified as:

$$
\frac{X_{\mathrm{vd}}}{u_{\mathrm{d}}}=\frac{K_{\mathrm{dv}}}{\frac{1}{\omega_{\mathrm{d}}} s+1},
$$

where $K_{\mathrm{dv}}$ is the gain coefficient and $\omega_{\mathrm{d}}$ is the natural frequency of proportional directional valve.

\subsection{Actuator and Loading System}

The actuator and loading system can be represented by the mass conservation equation and Newton's second law.

$$
\begin{gathered}
Q_{\mathrm{L}}=D_{\mathrm{m}} \frac{d \theta_{\mathrm{m}}}{d t}+C_{\mathrm{tm}} p_{\mathrm{L}}+\frac{V_{\mathrm{t}}}{4 E_{\mathrm{h}}} \frac{d p_{\mathrm{L}}}{d t}, \\
D_{\mathrm{m}} p_{\mathrm{L}}=J_{\mathrm{t}} \frac{d^{2} \theta_{\mathrm{m}}}{d t^{2}}+B_{\mathrm{m}} \frac{d \theta_{\mathrm{m}}}{d t}+T_{\mathrm{L}}, \\
T_{\mathrm{L}}=T_{\mathrm{f}}+T_{\mathrm{j}},
\end{gathered}
$$

where $D_{\mathrm{m}}$ is the displacement of hydraulic motor, $\theta_{\mathrm{m}}$ is the rotary angle of hydraulic motor, $C_{\mathrm{tm}}$ is the leakage coefficient, $V_{\mathrm{t}}$ is the total volume of hydraulic motor, $J_{\mathrm{t}}$ is the total inertia conversed to the hydraulic motor shaft, $B_{\mathrm{m}}$ is the viscous damping coefficient of hydraulic motor, $T_{\mathrm{L}}$ is the total loading torque, $T_{\mathrm{f}}$ is the friction torque, and $T_{\mathrm{j}}$ is the torque produced by the hydraulic loading pump.

The friction torque $T_{\mathrm{f}}$ can be represented by:

$$
T_{\mathrm{f}}=\left\{\begin{array}{cc}
T_{\mathrm{s}} & n_{\mathrm{m}}=0 \\
T_{\mathrm{c}} \operatorname{sgn}\left(n_{\mathrm{m}}\right) & n_{\mathrm{m}} \neq 0
\end{array},\right.
$$

where $T_{\mathrm{s}}$ is the static friction torque and $T_{\mathrm{c}}$ is the Coulomb friction torque.

$T_{\mathrm{j}}$ is the torque produced by hydraulic loading pump:

$$
T_{\mathrm{j}}=D_{\mathrm{pj}}\left(p_{\mathrm{j} 1}-p_{\mathrm{j} 2}\right),
$$

where $D_{\mathrm{pj}}$ is the displacement of the hydraulic loading pump and $p_{\mathrm{j} 1}, p_{\mathrm{j} 2}$ represents the pressure of highpressure chamber and low-pressure chamber in the hydraulic loading pump, respectively.

\section{SPEED CONTROL STRATEGY}

Fig. 3 shows the speed-control principle of proposed drive system. There are four inputs $\left(n_{\mathrm{in}}, n_{\mathrm{m}}, p_{\mathrm{s}}, p_{\mathrm{e}}\right)$ and three outputs $\left(f_{\text {in }}, u_{\mathrm{d}}, u_{\mathrm{t}}\right)$.

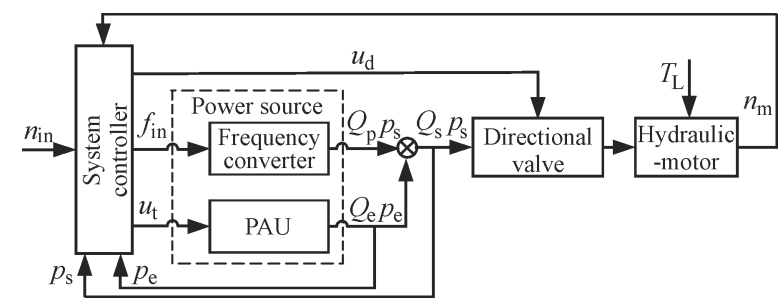

Fig. 3. Speed-control schematic diagram follows.

The speed-control strategy can be explained as

1". If $n_{\text {in }}>n_{\mathrm{m}}$, the hydraulic motor needs to accelerate. $f_{\text {in }}$ and $u_{\mathrm{d}}$ should be enlarged. If $p_{\mathrm{e}}>p_{\mathrm{s}}$, the PAU will be open to release energy. If $p_{\mathrm{e}}<p_{\mathrm{s}}$, the PAU is closed.

2. If $n_{\text {in }}<n_{\mathrm{m}}$, the hydraulic motor needs to decelerate. $f_{\text {in }}$ and $u_{\mathrm{d}}$ should be reduced. If $p_{\mathrm{e}}>p_{\mathrm{s}}$, the PAU is closed. If $p_{\mathrm{e}}<p_{\mathrm{s}}$, the PAU recovers energy.

3. If $n_{\mathrm{in}}=n_{\mathrm{m}}$, the electric-motor maintains its current speed, the proportional directional valve is used for speed-control. If $p_{\mathrm{e}}>p_{\mathrm{s}}$, the PAU is close. If $p_{\mathrm{e}}<p_{\mathrm{s}}$, it recovers energy. 
4. If $n_{\text {in }}$ is very small, the electric-motor maintains the allowable minimum speed. The proportional directional valve is used for speed-control. If $p_{\mathrm{e}}>p_{\mathrm{s}}$, the PAU is closed. If $p_{\mathrm{e}}<p_{\mathrm{s}}$, it recovers energy.

The proposed drive system is a complicated MIMO system coupled with strong nonlinear and time-varying parameters. The hybrid control strategy based on Proportion-Integration-Differentiation (PID), which only focuses on system input and output, was chosen to realize the control strategy. The detailed strategies of the three controlled-objects are discussed as below [9] and [13].

\section{Frequency converter}

The control expression is shown as Eq. (23), where the input-feedforward plays a major role in reference tracking, and the PID corrects the error caused by load disturbance. The input range of frequency converter is from 0 to $50 \mathrm{~Hz}$.

$$
f_{\text {in }}=\min \left[\max \left(\left|K_{\text {in }} \cdot n_{\text {in }}+u(k)\right|, 0\right), 50\right],
$$

where

$$
\begin{gathered}
u(k)=k_{\mathrm{fp}} e(k)+\lambda_{\mathrm{f}} k_{\mathrm{fi}} \sum e(i)+k_{\mathrm{fd}}[e(k)-e(k-1)], \\
e(k)=n_{\mathrm{in}}(k)-n_{\mathrm{m}}(k), \quad \lambda_{\mathrm{f}}=\left\{\begin{array}{ll}
1 & e(k) \leq e_{\mathrm{f}} \\
0 & e(k)>e_{\mathrm{f}}
\end{array}, k_{\mathrm{fp}}, k_{\mathrm{fi}}, k_{\mathrm{fd}}\right.
\end{gathered}
$$

represent the PID control parameters of frequency converter respectively, $e_{\mathrm{f}}$ is the integral separation threshold of frequency converter.

The parameter $K_{\text {in }}$ equals to the reciprocal of actuator speed-gain. In variable-speed drive, the frequency converter controls the speed of hydraulic motor along. If the frequency converter has an input frequency $f_{\text {in }}$, the hydraulic motor steady-state speed is $n_{\mathrm{s}}$ accordingly. The hydraulic motor speed-gain is defined as $n_{\mathrm{s}} / f_{\text {in }}$. And $K_{\text {in }}$ is defined as $f_{\text {in }} / n_{\mathrm{s}}$.

2. Proportional directional valve

The control expression is shown as Eq. (24), where the control voltage range is from -10 to $10 \mathrm{~V}$.

$$
\begin{aligned}
u_{\mathrm{d}}= & \min \left(\operatorname { m a x } \left(\left(k_{\mathrm{dp}} \cdot e(k)+\lambda_{\mathrm{d}} k_{\mathrm{di}} \cdot \sum_{i=0}^{k} e(i)+\right.\right.\right. \\
& \left.\left.\left.+k_{\mathrm{dd}} \cdot[e(k)-e(k-1)]\right),-10\right), 10\right),
\end{aligned}
$$

where $\lambda_{\mathrm{d}}=\left\{\begin{array}{ll}1 & e(k) \leq e_{\mathrm{d}} \\ 0 & e(k)>e_{\mathrm{d}}\end{array}, k_{\mathrm{dp}}, k_{\mathrm{di}}, k_{\mathrm{dd}}\right.$ represent the PID control parameters of proportional directional valve respectively and $e_{\mathrm{d}}$ is the integral separation threshold of directional valve.

\section{PAU}

The control expression is shown as Eq. (25). $n_{\mathrm{m} 0}$ is the allowable smallest speed of hydraulic motor, which is determined by the allowable minimum-speed of electric-motor.

$$
u_{\mathrm{t}}=\left\{\begin{array}{cc}
k_{\mathrm{tp}} \cdot e(k)+\lambda_{e} k_{\mathrm{ti}} \cdot \sum_{i=0}^{k} e(i)+k_{\mathrm{td}} \cdot[e(k)-e(k-1)] & n_{\mathrm{in}}>n_{\mathrm{m}}, p_{\mathrm{e}}>p_{\mathrm{s}} \\
k_{\mathrm{tp}} \cdot e(k)+\lambda_{e} k_{\mathrm{ti}} \cdot \sum_{i=0}^{k} e(i)+k_{\mathrm{td}} \cdot[e(k)-e(k-1)] & n_{\mathrm{in}}<n_{\mathrm{m}}, p_{\mathrm{e}}<p_{\mathrm{s}} \\
k_{\mathrm{tp}} \cdot e(k)+\lambda_{e} k_{\mathrm{ti}} \cdot \sum_{i=0}^{k} e(i)+k_{\mathrm{td}} \cdot[e(k)-e(k-1)] & n_{\mathrm{in}}=n_{\mathrm{m}}, p_{\mathrm{e}}<p_{\mathrm{s}} \\
k_{\mathrm{tp}} \cdot e(k)+\lambda_{e} k_{\mathrm{ti}} \cdot \sum_{i=0}^{k} e(i)+k_{\mathrm{td}} \cdot[e(k)-e(k-1)] & n_{\mathrm{in}}<n_{\mathrm{m} 0, p_{\mathrm{e}}<p_{\mathrm{s}}} \\
0 & \text { others }
\end{array}\right.
$$

where $\lambda_{e}=\left\{\begin{array}{ll}1 & e(k) \leq e_{\mathrm{e}} \\ 0 & e(k)>e_{\mathrm{e}}\end{array},, k_{\mathrm{tp}}, k_{\mathrm{ti}}, k_{\mathrm{td}}\right.$ represent the PID control parameters of PAU respectively, $e_{\mathrm{e}}$ is the integral separation threshold of PAU.

The proposed drive system will increase the control complexity. A lot of control parameters (shown in Eqs. (23) to (25)) should be determined before simulation. The tuning methods are discussed in [9].

\section{DYNAMIC SIMULATION}

Fig. 4 shows the AMESim-Simulink co-simulation model of proposed drive system. In AMESim, a large set of validated libraries of pre-defined components representing the hydraulic, electric or mechanical behaviour of the system can employed in creating the system simulation model [9] and [14]. In the co-simulation, the hydraulic model is established in AMESim while the control model is established in Simulink. The co-simulation combines the advantages of the two softwares. As shown in Fig. 4, the simulation model of loading system is simplified.

Because the proportional directional valve can switch the rotational direction of hydraulic motor easily, the loading system is not necessary to switch the load-torque direction. So the simplification of loading system does not influence the simulation results.

The principal parameters in the simulation model are shown in Table 1.

To comprehensively study the dynamic performance of proposed drive principle system, three typical variable-load disturbances are implemented: square-wave variable load; fast time-varying \& small disturbance variable load; slow time-varying \& large disturbance variable load. For comparisons, the simulations of the other three drive principle systems are also studied. 


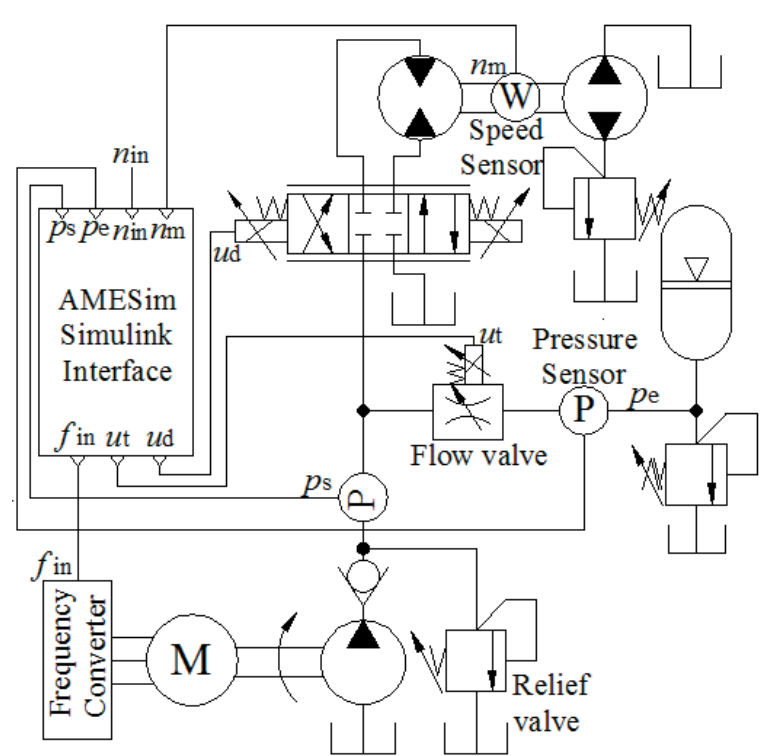

Fig. 4. AMESim-Simulink co-simulation model

Table 1. Principal parameters in simulation model

\begin{tabular}{|c|c|c|c|}
\hline Parameter & Value & Parameter & Value \\
\hline$D_{\mathrm{p}}$ & $20 \mathrm{~mL} / \mathrm{r}$ & $D_{\mathrm{m}}$ & $30 \mathrm{~mL} / \mathrm{r}$ \\
\hline$D_{\mathrm{pj}}$ & $30 \mathrm{~mL} / \mathrm{r}$ & $T_{\mathrm{IM}}$ & 3 \\
\hline$K_{\mathrm{f}}$ & $30 \mathrm{r} /(\min \cdot \mathrm{Hz})$ & $B_{\mathrm{m}}$ & $0.0166 \mathrm{Nm} /(\mathrm{r} / \mathrm{min})$ \\
\hline$J_{\mathrm{t}}$ & $0.1 \mathrm{kgm} 2$ & $V_{\mathrm{a} 0}$ & $6.3 \mathrm{~L}$ \\
\hline$p_{\mathrm{a} 0}$ & $2 \mathrm{MPa}$ & $T_{\mathrm{s}}$ & $4.47 \mathrm{Nm}$ \\
\hline$p_{\mathrm{cr}}$ & $10 \mathrm{MPa}$ & $T_{\mathrm{f}}$ & $13.3 \mathrm{Nm}$ \\
\hline$E_{\mathrm{h}}$ & $700 \mathrm{MPa}$ & $\rho$ & $850 \mathrm{~kg} / \mathrm{m} 3$ \\
\hline$\omega_{\mathrm{d}}$ & $20 \mathrm{~Hz}$ & $\omega_{\mathrm{t}}$ & $20 \mathrm{~Hz}$ \\
\hline
\end{tabular}

The expression of each controlled-object in the above three drive principle systems is the same as in the proposed drive principle system. Correspondingly, the conditions of simulations are the same, as well as the control parameters. The reference speed of the hydraulic motor is $600 \mathrm{r} / \mathrm{min}$ in all simulations. In the following texts and figures the numbers 1 to 4 represent the valve-controlled-motor drive, the variable-speed pump-controlled-motor drive, the variable-speed valve-controlled-motor drive and the proposed drive respectively.

\subsection{Square-Wave Variable-Load}

Fig. 5 shows the comparisons of hydraulic speed in the square-wave variable-load simulations, where the square-wave cycle lasts $10 \mathrm{~s}$. pload is the cracking pressure of loading valve (the proportional relief valve in the loading system).

Since the proportional directional valve in the variable-speed drive system keeps its maximum spool-opening without actuator speed regulation, the overshoot of curve 2 is the largest. Curve 3 has smaller overshoot and little adjusting time than Curve 2. Curve 4 has the smallest error in the four drive principle systems (detailed comparisons are shown in Table 2).

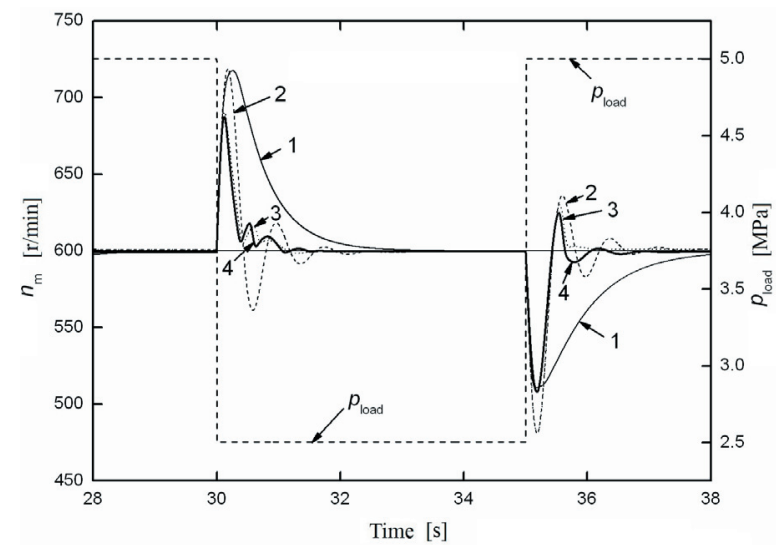

Fig. 5. Comparisons of hydraulic motor speed in square-wave variable-load simulations

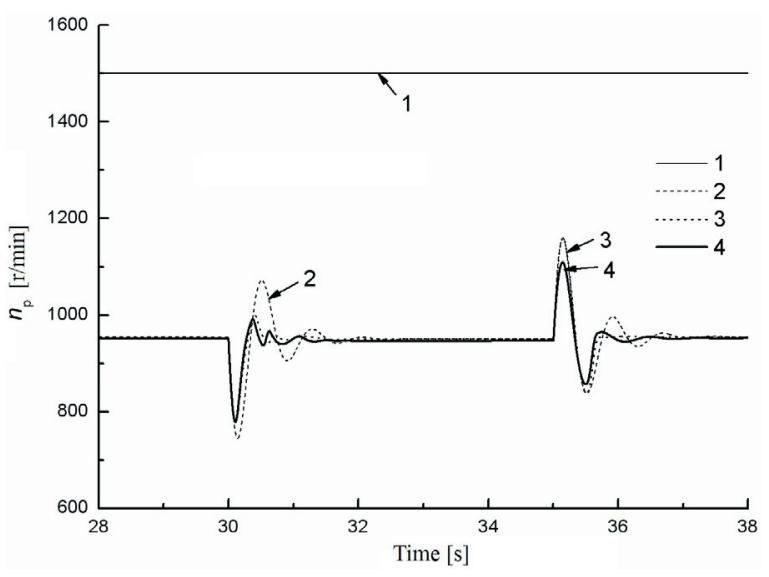

Fig. 6. Comparisons of electric-motor speed in square-wave variable-load simulations

Fig. 6 shows the comparisons of electric-motor speed in the square-wave variable-load simulations. The electric-motor speed is always $1500 \mathrm{r} / \mathrm{min}$ in the valve-controlled drive system. Curve 4 has the smallest change in the other three drive systems. Fig. 7 shows the control voltage comparisons of the proportional directional valve in the square-wave variable-load simulations.

The hydraulic power consumptions of systems using four different drive principles are shown in Fig. 8. They are calculated by the Eq. (26):

$$
P=p_{\mathrm{s}} \cdot Q_{\mathrm{s}} .
$$


The hydraulic power required by a valvecontrolled-motor drive system is always the largest. The hydraulic power of the proposed drive system is basically the same as in the other two drive systems.

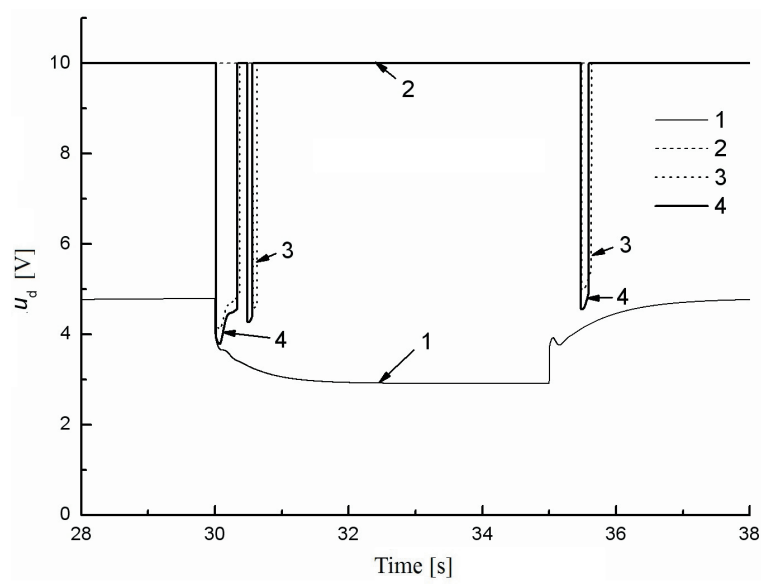

Fig. 7. Comparisons of directional valve control voltage in squarewave variable-load simulations

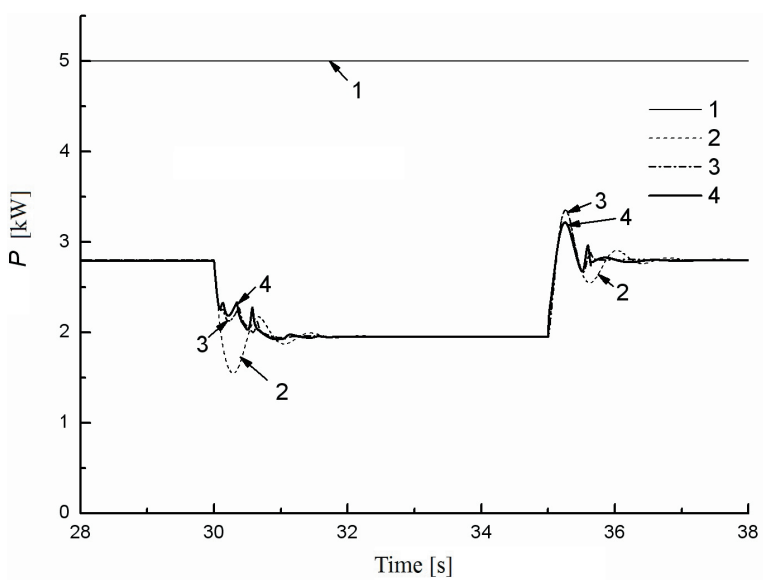

Fig. 8. Comparisons of hydraulic power consumptions in squarewave variable-load simulations

Table 2 shows the mean square errors (MSE) of hydraulic motor speed tracking and average hydraulic power consumptions in the square-wave variable-load simulations. It can be seen that the proposed drive system obtains the best reference-tracking precision on the basis of energy savings.

Table 2. MSEs and average hydraulic power consumption in square-wave variable-load simulations

\begin{tabular}{lcccc}
\hline System & 1 & 2 & 3 & 4 \\
\hline MSE [r2/min2] & 1223.34 & 653.01 & 448.75 & 301.76 \\
\hline Average hydraulic power $[\mathrm{kW}]$ & 5.00 & 2.38 & 2.40 & 2.39 \\
\hline
\end{tabular}

Where $M S E=\frac{1}{n} \sum_{i=0}^{n}\left(n_{\mathrm{in}}(i)-n_{\mathrm{m}}(i)\right)^{2}, \quad n$ is the numerical value of sampling times.

\subsection{Fast Time-Varying \& Small-Disturbance Variable-Load}

The loading pressure of fast time-varying \& smalldisturbance variable-load is represented by:

$$
p_{\text {load }}=4+0.5 \cdot \sin (2 \pi \cdot 1) \mathrm{MPa} \text {. }
$$

Fig. 9 shows the comparisons of hydraulic motor speed in the fast time-varying \& small disturbance variable-load simulations. The error in the system 2 is the largest, which even reaches to $\pm 40 \mathrm{r} / \mathrm{min}$. The error is about $\pm 25 \mathrm{r} / \mathrm{min}$ in the Curve 1 . Curve 4 has the smallest speed tracking error in the four drive systems.

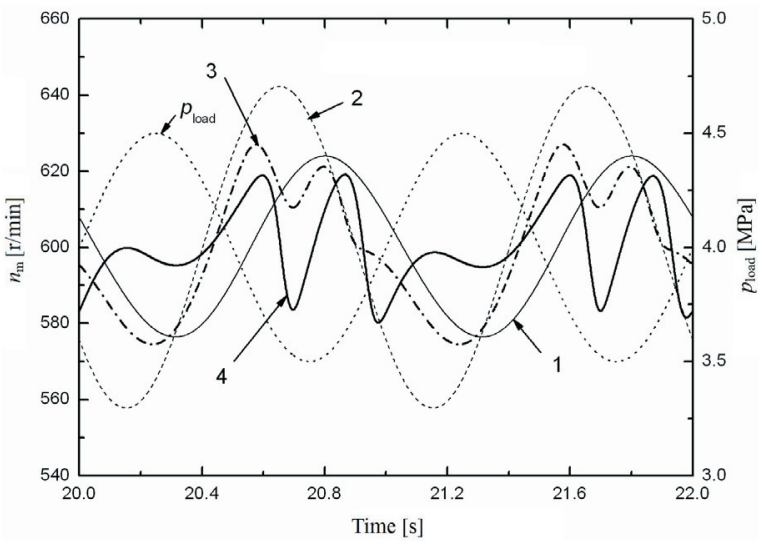

Fig. 9. Comparisons of hydraulic motor speed in fast time-varying \& small-disturbance variable-load simulations

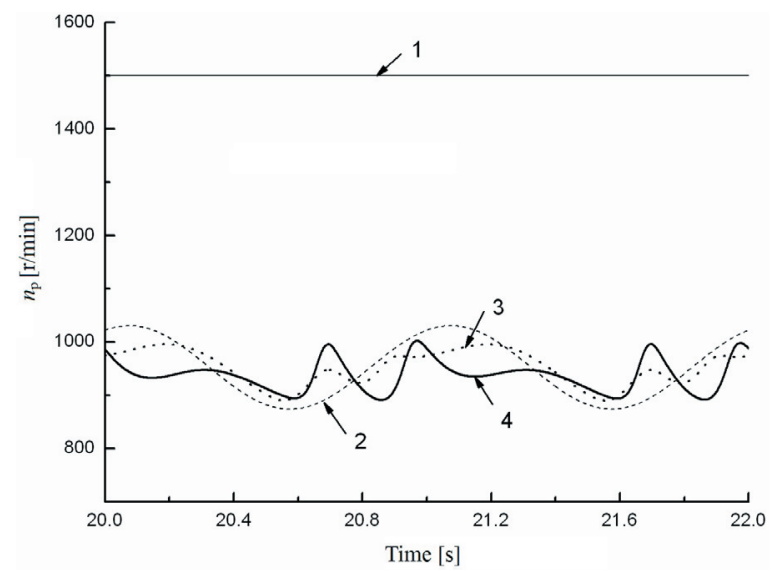

Fig. 10. Comparisons of electric-motor speed in fast time-varying \& small-disturbance variable-load simulations

Fig. 10 shows the electric-motor speed comparisons in the fast time-varying \& smalldisturbance variable-load simulations. Fig. 11 shows 
the comparisons of hydraulic pump outlet pressure. In Curve 4, there are some big pressure overshoots resulting from the release of oil by PAU.

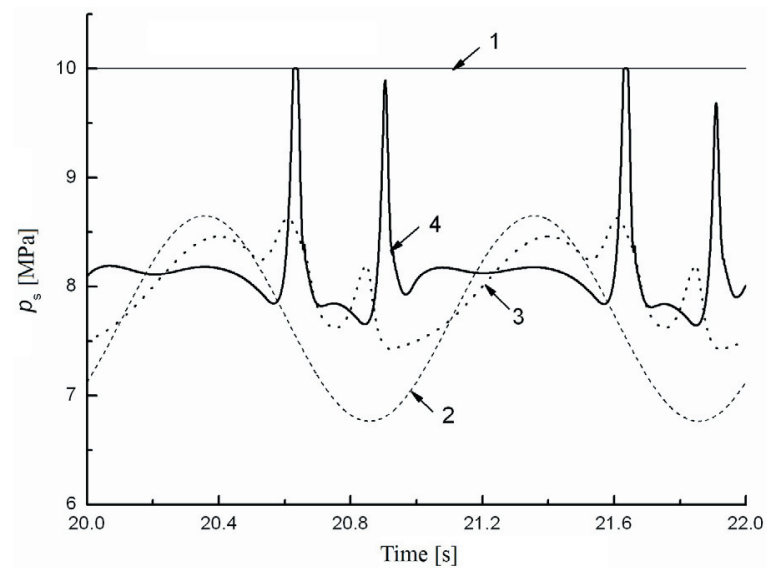

Fig. 11. Comparisons of hydraulic pump outlet pressure in fast time-varying \& small-disturbance variable-load simulations

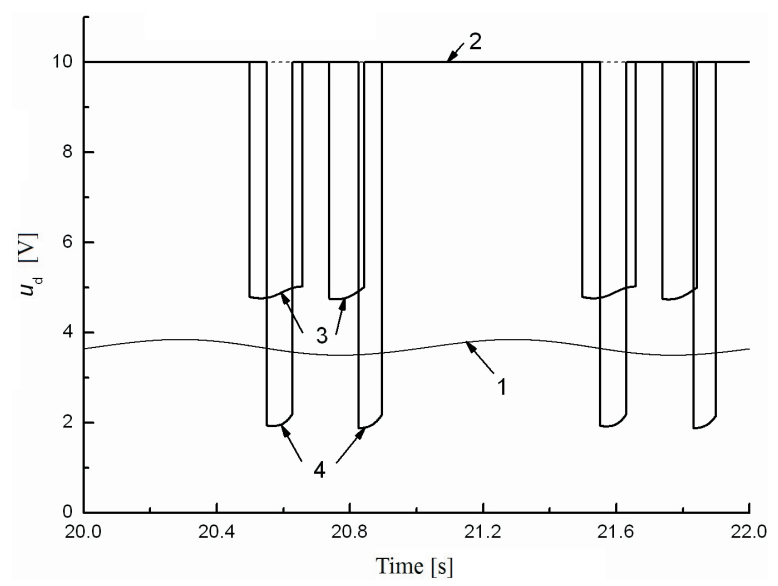

Fig. 12. Comparisons of proportional directional valve control voltage in fast time-varying \& small-disturbance variable-load simulations

Fig. 12 shows the comparisons of proportional directional valve control voltage. The control voltage in Curves 3 and 4 decreases rapidly so as to overcome the speed overshoot caused by disturbances. Fig. 13 shows the comparisons of hydraulic power consumption.

Table 3 shows the MSEs of hydraulic motor speed tracking and average hydraulic power consumption. The MSE of the proposed drive system is the smallest in the four drive systems while the hydraulic power consumption is only half of the valve-controlledmotor drive system.

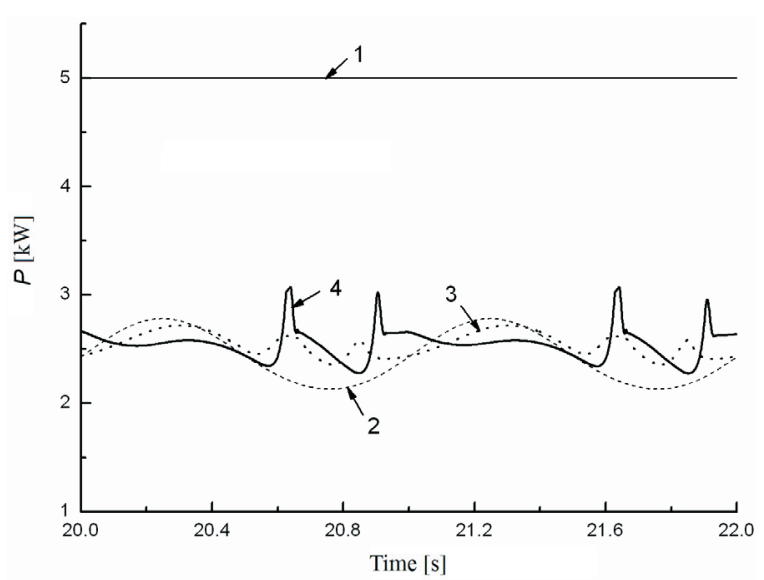

Fig. 13. Comparisons of hydraulic power consumption in fast timevarying \& small-disturbance variable-load simulations

Table 3. MSEs and average hydraulic power consumption in fast time-varying \& small-disturbance variable-load simulations

\begin{tabular}{lcccc}
\hline System & 1 & 2 & 3 & 4 \\
\hline MSE [r2/min'2] & 282.97 & 892.08 & 286.12 & 109.29 \\
\hline Average hydraulic power $[\mathrm{kW}]$ & 5.00 & 2.44 & 2.54 & 2.54 \\
\hline
\end{tabular}

\subsection{Slow Time-Varying \& Large-Disturbance Variable-Load Simulation}

The slow time-varying \& large-disturbance variableload is represented by:

$$
p_{\text {load }}=4+2 \cdot \sin (2 \pi \cdot 0.1) \mathrm{MPa} .
$$

Fig. 14 shows the comparisons of hydraulic motor speed. The speed tracking error in Curve 1 is the biggest, because the spool-opening of the directional valve changes dramatically so as to suppress the disturbance.

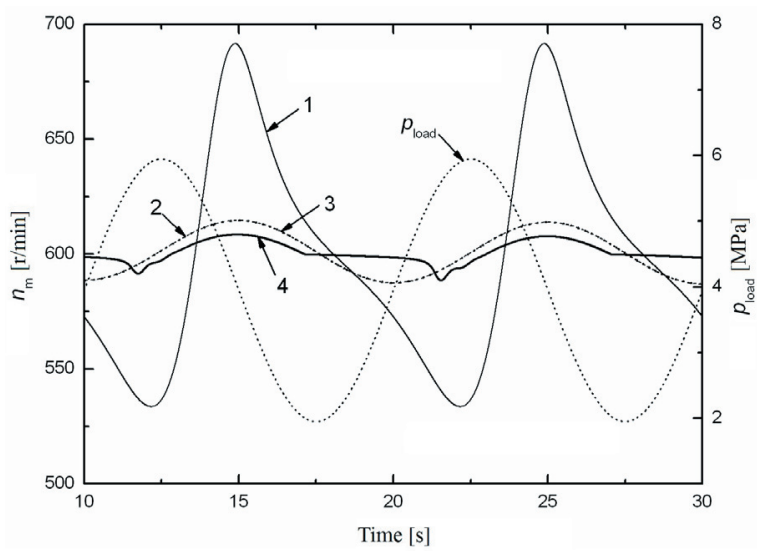

Fig. 14. Comparisons of hydraulic motor speed in slow timevarying \& large-disturbance variable-load simulations 
Fig. 15 shows the comparisons of directional valve control voltage. And Fig. 16 shows the comparisons of hydraulic pump outlet pressure.

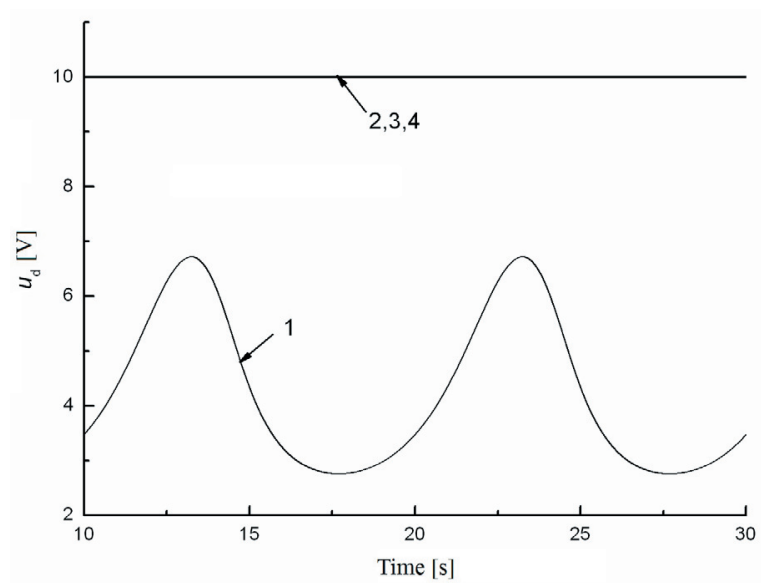

Fig. 15. Comparisons of directional valve control voltage in slow time-varying \& large-disturbance variable-load simulations

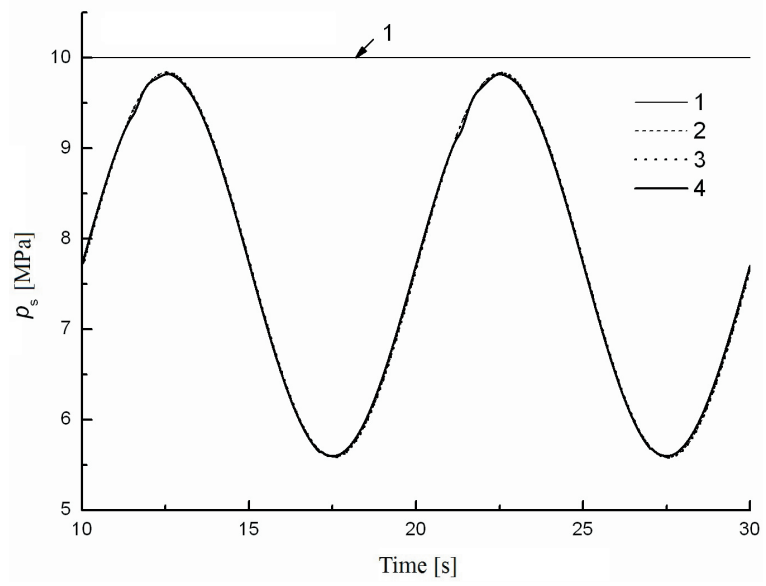

Fig. 16. Comparisons of hydraulic pump outlet pressure in slow time-varying \& large-disturbance variable-load simulations

Fig. 17 shows the hydraulic power consumptions in the four drive systems. It can be seen that the valve controlled drive system has the highest power consumption. The hydraulic power consumptions in the other three drive systems are almost the same.

Table 4 shows the MSEs of hydraulic motor speed tracking and average hydraulic power consumption. The MSE in proposed drive system is the smallest in the four drive systems while the hydraulic power consumption is basically the same as that seen in the variable-speed drive system and in the variable-speed valve-controlled-motor drive system.

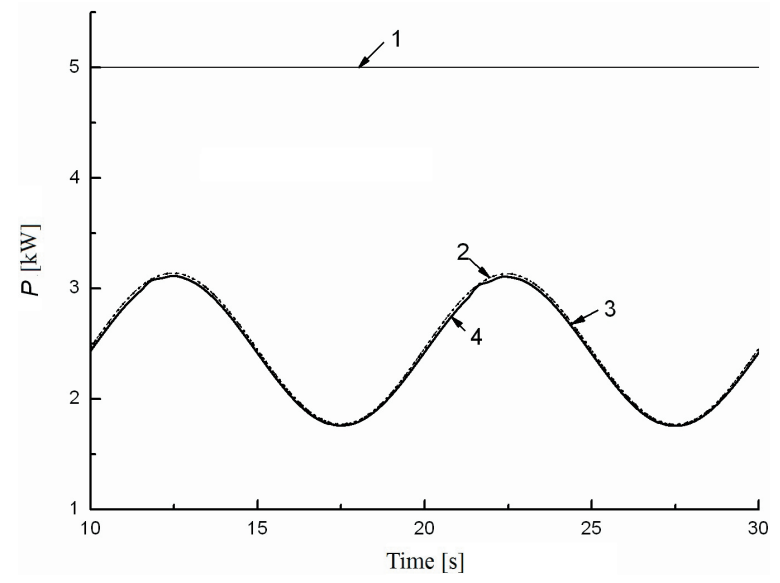

Fig. 17. Comparisons of hydraulic power consumption in slow time-varying \& large-disturbance variable-load simulations

Table 4. MSEs and average hydraulic power consumption in slow time-varying \& large-disturbance variable-load simulations

\begin{tabular}{lcccc}
\hline System & 1 & 2 & 3 & 4 \\
\hline MSE [rmin'2] & 2204.49 & 89.63 & 89.62 & 20.99 \\
\hline Average hydraulic power $[\mathrm{kW}]$ & 5.00 & 2.45 & 2.45 & 2.42 \\
\hline
\end{tabular}

\section{CONCLUSIONS}

A variable-speed valve-controlled-motor drive system with an accumulator-based power-assisted unit is a good solution for improving the response and control precision of hydraulic motor drives. However, it is a complicated non-linear MIMO control system coupled with time-varying that worsens dynamic performance. Therefore, a PID based hybrid control strategy is presented.

The novel drive principle will increase the cost of the drive system and control complexity, but the cosimulation results show that it not only achieves the expected energy savings target, but also demonstrates a good anti-interference performance.

\section{ACKNOWLEDGEMENT}

This research was supported by the National Natural Science Foundation of China (Grant No. 51205099), Zhejiang province key science and technology innovation team (Grant No. 2010R50003-3).

\section{REFERENCE}

[1] Ristic, M. (2008). Conversant technology - New key aspects: Development of variable speed drives. Proceedings of International Fluid Power Conference, Dresden, p. 93-108. 
[2] Manasek, R. (2000). Simulation of an electro-hydraulic load-sensing system with AC motor and frequency changer. Proceeding of the 1st FPNI-PhD Symposium, Hamburg, p. 311-324.

[3] Peng, T.H., Xu, B., Yang, H.Y. (2004). Development and research overview on variable frequency hydraulic technology. Journal of Zhejiang University (Engineering Science), vol. 38, no. 2, p. 215-221, DOI: 10.3785/j.issn.1008-973X.2004.02.019. (In Chinese)

[4] Helduser, S. (2003). Improved energy efficiency in plastic injection molding machines. The $8^{\text {th }}$ Scandinavian International Conference on Fluid Power, Tampere, p. 1219-1229.

[5] Xu, B., Yang, J., Yang, H.Y. (2005). Comparison of energy saving on the speed control of the VVVF hydraulic elevator with and without the pressure accumulator. Mechatronics, vol. 15, no. 10, p. 11591174, DOI:10.1016/j.mechatronics. 2005.06.009.

[6] Lovrec, D., Kastrevc, M., Ulaga, S. (2009). Electrohydraulic load sensing with a speed-controlled hydraulic supply system on forming-machines. International Journal of Advanced Manufacture Technology, vol. 41, no. 11 , p. 1066-1075, DOI:10.1007/s00170-0081553-y.

[7] Chiang, M.-H. (2011). A novel pitch control system for a wind turbine driven by a variable-speed pumpcontrolled hydraulic servo system. Mechatronics, vol. 21, no. 4, p. 753-761, DOI:10.1016/j. mechatronics.2011.01.003.

[8] Marinković, Z., Marinković, D., Petrović, G., Milić, P. (2012). Modelling and simulation of dynamic behaviour of electric motor driven mechanisms. Technical Gazette, vol. 19, no. 4, p. 717-725.

[9] Xu, M., Jin, B., Chen, G.J., Ni, J. (2013). Speedcontrol of energy regulation based variable-speed electrohydraulic drive. Strojniški vestnik - Journal of Mechanical Engineering, vol. 59, no. 7-8, p. 433-442, DOI:10.5545/sv-jme.2012.911.

[10] Shen, H.K., Jin, B., Chen, Y. (2006). Research on variable-speed electrohydraulic control system based on energy regulating strategy. ASME International Mechanical Engineering Congress and Exposition, Chicago.

[11] Xu, M., Jin, B., Shen, H.K., Li, W. (2010). Analysis and design of energy regulation device in energy regulation based variable speed electro-hydraulic control system. Chinese Journal of Mechanical Engineering, vol. 46, no. 4, p. 136-142, DOI:10.3901/JME.2010.04.136. (in Chinese)

[12] Xu, M., Jin, B., Yu, Y.X., Shen, H.K., Li, W. (2010). Using artificial neural networks for energy regulation based variable-speed electrohydraulic drive. Chinese Journal of Mechanical Engineering, vol. 23, no. 3, p. 327-335, DOI:10.3901/CJME.2010.03.327.

[13] Liu, G.P., Daley, S. (2000). Optimal-tuning nonlinear PID control of hydraulic systems. Control Engineering Practice, vol. 8, no. 9, p. 1045-1053, DOI:10.1016/ S0967-0661(00)00042-3.

[14] Tič, V., Lovrec, D. (2012). Design of modern hydraulic tank using fluid flow simulation. International Journal of Simulation Modelling, vol. 11, no. 2, p. 77-88, DOI:10.2507/IJSIMM11(2)2.202. 